\title{
Information systems for eco-effective manufacturing
}

\author{
B.S. Kim ${ }^{1}$, K.H. Park', and B.C. Kim ${ }^{3}$ \\ ${ }^{1}$ Graduate School of Management, Korea Advanced Institute \\ of Science and Technology(KAIST) \\ 373-1 KuSeong-Dong, YuSeong-Ku, Taejon 305-701, Korea \\ Tel: ++82-42-869-4355, Fax: ++82-42-869-2910 \\ e-mail:kbs@mgt.kaist.ac.kr \\ ${ }^{2}$ Lab. PRISMa, INSA de Lyon \\ 69621 Villeurbanne Cedex, France \\ Tel: ++33-4-72 43 84 87, Fax: ++33-4-72438518 \\ e-mail: khpark@if.insa-lyon.fr \\ ${ }^{3}$ Department of Industrial Management, KAIST \\ 373-1 KuSeong-Dong, YuSeong-Ku, Taejon 305-701, Korea \\ Tel: $++82-42-869-2912$, Fax: $++82-42-869-2910$ \\ e-mail: bckim@sorak.kaist.ac.kr
}

\begin{abstract}
Integration of environmental aspects on manufacturing has been considered. Design for environment based on life cycle thinking is one of the approaches. To transfer adequate scientific environmental information into manufacturing process and to exchange socio-economic and ecological information, the information system for eco-effective manufacturing is very essential. Design, structure, and implementation of such information systems are described. Behavioural aspects of the systems such as attitude of users and training are also mentioned.
\end{abstract}

\section{Keywords}

environment, manufacturing, information, life cycle, product planning 
The awareness of environmental management is becoming essential in today's industrial situation, as major firms recognise the importance of environmental responsibility for their long term business. Environmental performance becomes a prerequisite for doing business.

There are a number of global trends that make it imperative for manufacturing firms to become more aware of the environmental implications of their product and process designs. The legislation that requires producers to take-back products at the end-of-life is being enacted. Environmental labels, which promote the development of environmentally friendly product and provide environmental performance information to consumers, are becoming actual industrial standards. Environmental codes of management practice series are becoming more prevalent. Many government agencies are taking aggressive steps to ensure that manufacturers are responsible for recovery of products and materials at the end of their useful lives. Consumers also have concerned about the environmental friendliness of the products that they purchase. A number of research articles have discussed about environmentally conscious consumers, who show the behaviour of buying environmentally conscious products although the products are inferior to other products in price and convenience, or perceived as so (Coddington, 1993).

The object of this task is to visualise the conceptual model of information systems for eco-effective manufacturing. Firstly, studies for design for environment are reviewed briefly, and the need of information systems for eco-effective manufacturing is described. The planning, design and implementation of information systems into manufacturing are followed. Finally, some organisational aspects are mentioned.

\section{DESIGN FOR ENVIRONMENT}

Design for Environment (DFE) is defined as systematic consideration of design performance with respect to environmental, health, and safety objectives over the full product and process life cycle (Fiksel, 1996). It seeks to eliminate the potential negative environmental impacts which result from particular products or processes throughout its entire life cycle by systematically assessing, evaluating, and addressing these potential problems during manufacturing. Although some product and process improvements can be accomplished after design, the greatest impact at the lowest cost is usually realised only when improvements are incorporated into initial designs, especially at the planning phase (TB\&E).

DFE aims to bridge the gap between two traditionally separate functions: manufacturing and environmental management. The goal of DFE is to bring these two functions into closer contact and address product life cycle issues that are often ignored. Perhaps the most important factor in changing industry attitudes has been the realisation that paying attention to environmental responsibility can actually increase profitability. Reducing pollution at the source and designing products and processes in ways that enhance environmental quality generally result in the higher 
productivity and reduced operating costs, and may also increase the market share. Typical manufacturing proceeds through a number of stages as followings:

\section{Product planning}

Integrated product development can be defined as a process whereby all functional groups such as engineering, manufacturing, marketing that are involved in a product life cycle participate as a team in the early understanding and resolution of key product development issues. Well-structured product planning model makes the basis of product design. In addition, it considers business administrative and strategic aspect of product.

The eco-effective product design is defined as the systematic setting of environment-oriented goals in the product design process (Frei and Züst, 1997), and that is why the importance of product planning, the early phase of product design, has arisen. Planning of eco-effective product is the interface between product design, management, and environment. So far, environmental aspects have not been taken into account in product planning. However surely one should also consider environmental aspects in product planning because of the situation described above.

\section{Task clarification}

In this stage the goals that a product is expected to meet are developed. At this phase, the tasks performed during the development process are defined, and the problems are outlined.

\section{Conceptual design}

Once the general goals of a product or process have been outlined, more specific plans for achieving these goals are developed. At this phase, a number of different concepts are usually created and evaluated to find the one that best addresses product goals. This is also a critical step for incorporating DFE concepts, for it is at this stage that the general goals are developed into a realistic course of action.

\section{Embodiment design}

The next stage is to create a more complete description of the product or process, short of the specific detail work. The fundamental engineering concepts that were established in the conceptual design stage are elaborated to ensure their feasibility, and that they will work in the context of the product as a whole. When this stage has been completed, a final system layout for the product is produced.

At last, in this stage of manufacturing, the layout that was developed is turned into a completed set of engineering drawings and production methods that are used to produce the actual product. No major changes should occur at this phase, as it is primarily to flesh out specific technical details, specifications, and tolerances that will allow the product to be produced. DFE activities at this stage should be focused on helping the designer improve the environmental performance of specific systems, and serve to evaluate final impacts so that environmental performance of future products or redesigns can be improved. 


\section{APPLICATION OF INFORMATION SYSTEM FOR IMPLEMENTING DESIGN FOR ENVIRONMENT}

\section{Need of integrating information system(IS) in implementing DFE}

The integration of DFE and IS has not discussed in detail, because the research about DFE became activated in early 1990s, while the development of information technology and the application of it in organisation are discussed actively in 1980s.

There is the need for cooperation between environmental scientists and manufacturing managers so that they can develop eco-effective manufacturing strategies for ecosystem. This need for co-operation suggests that the management of environmental systems needs the information available from information technological system together with the sensitivity to economic and ecological pressures that may result from such decision making (Moffatt, 1990).

According to Agenda 21, which was adopted in the Rio Earth Summit in 1992, decision making based on adequate information requires both bridging the data gap and improving information availability. In spite of their usefulness as methods of systematic data collection and analysis, their potential application in eco-effective manufacturing is very limited.

\section{IS planning for DFE}

Environmental quality planning has been hampered by an inability to collect and handle large amounts of environmental and manufacturing information effectively. The development of environmental IS could alleviate many of the problems associated with information processing. Especially on large corporations, to cope with the increase in the size, complexity, and dynamism of corporations, managers are implementing IS to aid their decision making process.

Environmental planning activities must not only interact within the engineering disciplines but also with public and governmental agencies outside the project (Fabrick and O'rourke, 1982).

\section{Consideration of different systems}

There are several options for developing a comprehensive IS or information infrastructure for DFE programs. The options available to individual companies are changing dependent upon contemporary information technology, and the options realised in them are also changing as rapidly as the need for DFE programs.

The features and characteristics of IS for DFE is depending on its phase, i.e., the decision for product planning and for embodiment design is completely different. Product planning and embodiment design are two representative phases in Design process. Relatively, the real implementations have been progressed for the embodiment phase, because traditionally the narrow meaning of DFE has been for embodiment design. 


\section{INFORMATION SYSTEM FOR EMBODIMENT DESIGN}

On the technical side industrial ecology offers specific engineering and operational programs for data gathering, technology deployment and product design. The techniques and technologies of real-time environmental monitoring are becoming increasingly sophisticated, and will be integrated using information technology as a practical tool for mapping and managing environmental impacts.

Environmental data collection and management, on-line guidance, data and design analysis, and integration of DFE techniques into standard CAD and CAE systems are key issues relating to design and design tools (Fiksel, 1996). Before considering tools, it should be determined that which steps in the design and implementation phases would benefit most then consider the general applicability of the tool to the areas of need and examine the specific support and implementation requirements. Applicability to manufacturing stages, applicability to product life cycle stages, and degree of decision support are primary attributes may be used to classify DFE tools.

A pioneering example of the corporate use of information technology to integrate environmental, technical, and management data is provided by Johnson \& Johnson, the international health-care products manufacturer (Tibbs, 1991). In addition, the Consortium on Green Design and Manufacturing was formed in 1993. It developed several softwares for implementing DFE (CGDM). Other known tools for embodiment design are biased to LCA tools, because LCA is representative methods that can be well-measurable and quantifiable.

\section{INFORMATION SYSTEM FOR PRODUCT PLANNING}

\subsection{Which decisions should be made?}

Manufacturing itself is neutral on environmental issue, i.e., it is not inseparably related with environmental consideration. Basically manufacturing companies are profit oriented, so even though there are some ethical issues to discuss, it is natural that environmental consideration is not prior to pursuit for profit. Surely one should also consider environmental aspects in manufacturing because of the situation described above. To describe about the required decisions, activities around the company should be considered firstly. Besides of tangible exchanges, it is need to find the information flows to describe the requirement of decision support, i.e., to find what are required to construct appropriate IS. Generally, the information may be used for the environmental improvement of manufacturing systems, to support corporate policy detail targets via appropriate documentation and communication. The information flows can be depicted like Figure 1. Information flow with environment is not bidirectional, because the information is useful only for people related.

They can be categorised as production system definition that considers production chain, design for business excellence that considers stakeholders and market, and environmental considerations for product. Decisions that should be made in 


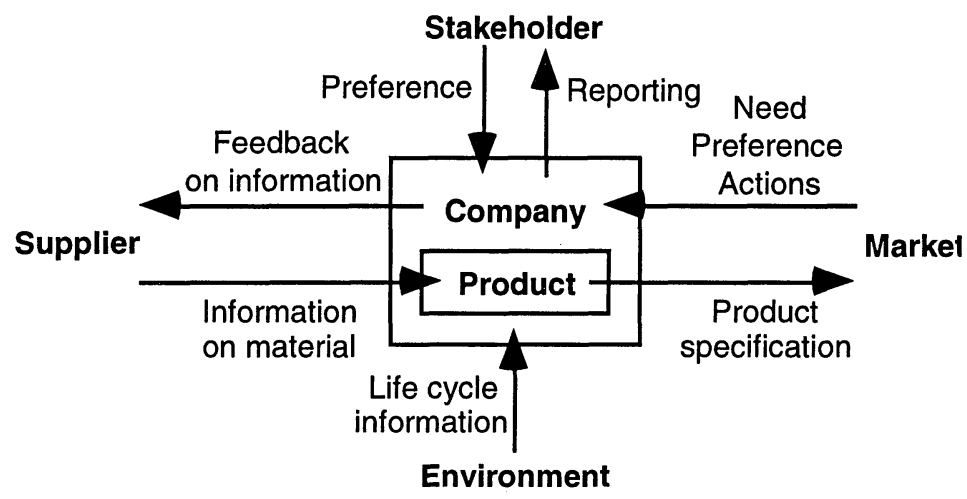

Figure 1 Information flows among related groups.

product planning phase can be summarised as product systems definition, design for business excellence, and environmental considerations for product.

\subsection{Structure of Information System}

\section{Database}

The first step toward a solution in almost every problem is to access existing information. The availability of data in usable formats is critically important because they form the infrastructure for initial project planning. Information on alternative materials or processes, including relevant parameters such as cost, effect on product performance, environment, energy, and economic impact, would be very useful.

\section{Models and corresponding $D B$}

The models are classified into as followings.

- Market models are represented by identification of the needs of the market, analysis of the reaction of the market, and judgement models for product according to the preference of stakeholders

- Life cycle models are represented by production systems definition model and rough modelling of life cycle inventory based on available data.

- Multidimensional environmental models are almost same concept with impact assessment models.

- Other decision support models are provided by decision theory for general business administration, and they are still developing now. What is important is not to know models and methods as many as possible, but understand which models are needed in current decision making and realise them into IS. Uncertainty resolving models are used to evaluate choices in the face of uncertainty, and to consider what technical and business strategies the company might adopt in response to different market or competitive scenarios. 
- Case models are available from both success and failure. It is possible to extract other models from cases, but sometimes case itself can be very useful to decision makers. Even though it is hard to extract quantitative models from cases, they can act as metaphor or surrogate model.

\section{Interfaces}

- General human interfaces are normally common in every IS, because their objective is to make present results easier and more understandable. There are so many theories that assert the string point of certain interface technique. They are not described in detail here.

- Global operating logic provides better analysing ability, such as intelligent agents to facilitate search and data mining tools. In addition, the system should incorporate a well-defined security protocol. Because environmental matter is interdepartmental and interdisciplinary, there are so many persons from several groups who are related in updating information in database. So the problem of access privilege is arisen because some data should be consistent and identical with each other.

- Interchanging information between human and IS is important because if the system is designed to be interactive, decision makers also can make their integrated results and give back some feedback to the system, mainly to another model, to progress next step. This also means that continual improvement of database and models is possible, and with this change and improvement, environmental and business learning cycles also can be expected.

One valuable thing to mention is the dynamic feature of the data. There is no definite information about the future status of data. All thing that decision makers can do is facilitating the existing data and revising it as new data set, based on the appropriate models. The set of expected data will be compared with real data, after embodiment and introducing in the market. Making new set of data is one of the most representative contents of the feedback phase.

\subsection{Other components for facilitating implementation}

\section{Linking function for databases}

It facilitates the linkage between databases and models. Some DBMS would be used for linking database to models.

\section{Transferring function}

This function is used for integrating several data and models. It supports problem structuring and formulation. Surely it can be implemented in each models, depending on the design of IS.

\section{Reporting function}

One of the function is the reporting to user and the other related groups. It contains the display format and appropriate environmental contents for decision makers and stakeholders or suppliers. Depending on the characteristics of information, there can be several kinds of format for reporting. Some of them are predefined according to 


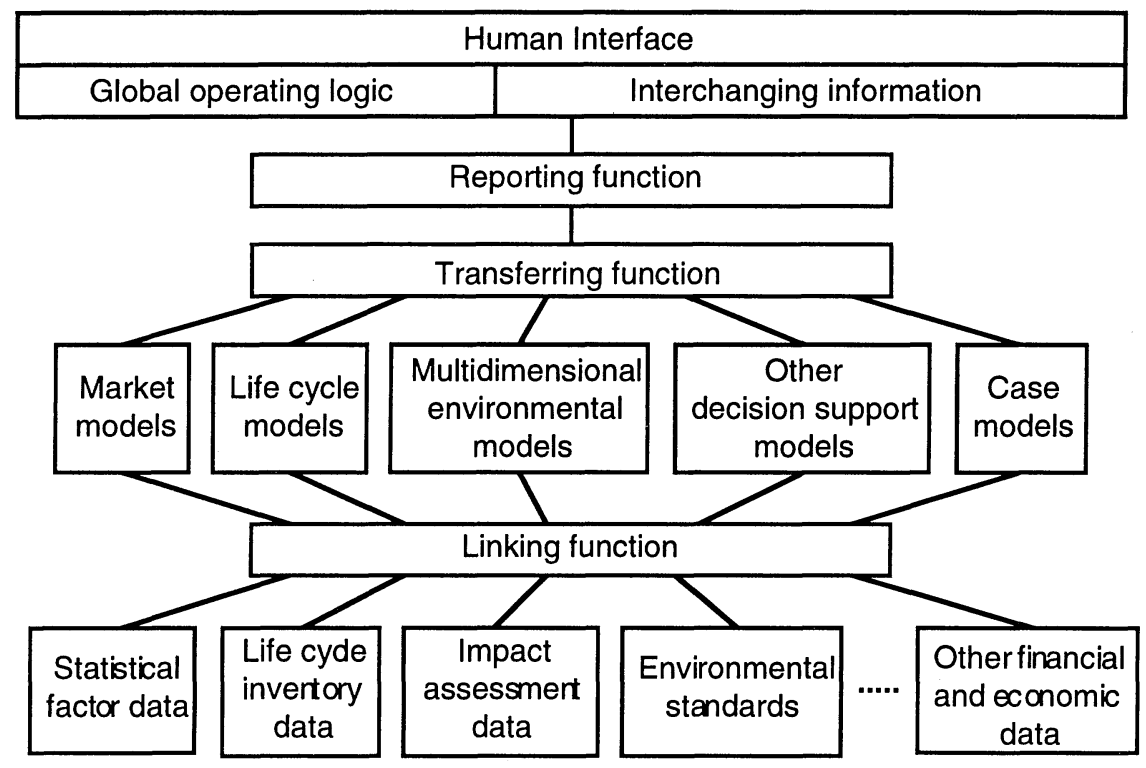

Figure 2 Structure of IS for eco-effective manufacturing.

the traditional format of company. The other is the input to other phases in product design, because the ultimate object of product planning is the development of a product. So, it should transfer all information needed by later phases.

In summary, the structure of IS for eco-effective manufacturing can be depicted like Figure 2.

\section{BEHAVIOURAL ASPECT OF INFORMATION SYSTEM FOR DESIGN FOR ENVIRONMENT}

\section{Supports from organisation}

When planning the IS it will have to be supported at all levels of the organisation. The project plan has to be supported mainly at an operational level. In addition, it has been suggested that top management is responsible for the development and implementation of an organisation's strategy. Since IS can have a significant strategic impact, top management also needs to take responsibility for fostering IS with the potential to provide this impact (Lederer, 1988).

\section{Attitude of users}

Because end-users must learn a variety of new skills and because they must adjust to a new work environment, management must provide them with substantial support. One should account for industry-specific characteristics. Each industry has its own special applications; in turn, end users of these applications display 
attitudes or behaviours that are different (Culpan, 1995). Many studies of IS implementation support the positive relationship between usefulness and system use (Keil et al., 1995). Favourable attitudes of users are associated with implementation success.

\section{Training}

Training should begin prior to implementing a system. Before training, however, you must make important decisions about the daily processes of your business.

IS for DFE, however, are difficult to have a concrete training system because it is at its developing stage in many cases. So, metaphor or surrogate model will be useful for training operators.

With regarding quality of information, if the information provided to IS has questionable quality, the results obtained by the most sophisticated computer system will also be questionable. Significant training must be placed at the data sampling and analysis activities of the institutions which provide information to the IS. This training element should be considered as a requirement for the successful implementation of IS for eco-effective manufacturing.

\section{CONCLUSION AND RESEARCH RECOMMENDATIONS}

Information technology has offered advantages on the aspect of speed, productivity, convenience. However, the construction of IS for eco-effective manufacturing is not simply a technical effort. Rather, it will represent new capabilities of firms and involve the whole organisation. Therefore, models for the process by which the IS are embedded in organisations should be developed.

At present, it is hard to apply this idea into practice because it needs the company-wide agreements on the importance of product planning beforehand. However, it provides a road map for the kind of life cycle thinking and analytic processes that are necessary to truly integrate environmental and business strategies. Even partial automation of this structure can yield significant benefits to a manufacturing organisation. This normative model should be applied to real situation and receive feedback if possible.

The further research is needed, with differentiating each phase of DFE. All of the phases are related with manufacturing issue, but the detail characteristics of the IS for the phases can be perfectly different. Moreover, the way for incorporating complex life cycle information should be systematised.

\section{REFERENCES}

CGDM (The Consortium on Green Design and Manufacturing). Software Tools, http://greenmfg.me.berkeley.edu/green/SoftwareTools/SoftwareTools.html.

Coddington, Walter (1993) Environmental Marketing, McGraw-Hill.

Culpan, Oya (1995) Attitudes of end-users towards information technology in manufacturing and service industries. Information \& Management, 28, 16776. 
Fabrick, Martin N. and O'rourke, Joseph J. (1982) Environmental Planning for Design and Construction. John Wiley \& Sons.

Fiksel, Joseph (1996) Design for Environment: Creating Eco-Efficient Products and Processes, McGraw-Hill.

Frei, Michael and Züst, Rainer (1997) The Eco-effective Product Design - The Systematic Inclusion of Environmental Aspects in Defining Requirements, in Life Cycle Networks (ed. F. L. Krause and G. Seliger), Chapman \& Hall, 16373.

Keil, Mark, Beranek, Peggy M. and Konsynski, Benn R. (1995) Usefulness and ease of use: field study evidence regarding task considerations. Decision Support System, 13, 75-91.

Lederer, Albert L. and Mendelow, Arbrey L. (1988) Convincing Top Management of the Strategic Potential of Information systems. MIS Quarterly, December, 525-34.

Moffatt, I. (1990) the Potentialities and Problems Associated with Applying Information Technology to Environmental Management. Journal of Environmental Management, 30, 209-20.

TB\&E (MIT Program on Technology, Business \& Environment). Implementing DFE, http://web.mit.edu/ctpid/www/tbe/primer/page2.html.

Tibbs, Hardin (1991) Industrial Ecology: An Environmental Agenda for Industry, http://www.sustainable.doe.gov/industrial/tibbs/tibbs.html.

\section{BIOGRAPHY}

BeomSeok Kim is doctoral candidate of Graduate School of Management, KAIST. He obtained M. S. in management and policy from KAIST, and worked as a visiting researcher in Institute for Industrial Engineering and Management, Swiss Federal Institute of Technology (ETH) Zurich. Currently he is interested in the application of decision support system for life cycle based eco-effective product design and business activities.

KyungHye Park is a doctoral candidate of applied computer science and production management at INSA in Lyon. After acting as a full-time teaching assistant at KAIST for 5 years in the Department of Management Science, she has worked as a researcher in the lab. PRISMa since 1993. She has presented some articles on international conferences such as IMS, MCPL, ETFA, GI, IEPM, etc. Her research interests include computer integrated manufacturing system, virtual or extended enterprise information system, and intranet/extranet.

Byung Chun Kim is a professor and the chairman of Department of Industrial Management in KAIST. He obtained his M.S. and $\mathrm{Ph}$. D. from Iowa State University in statistics and statistical computing respectively. Currently $\mathrm{He}$ is interested in experimental design, linear models applications, computer networking system, and environmental management. Prof. Kim had served as director of Computer Center of KAIST for 7 years. 